\section{Evaluation of a} breast self-

examination (BSE) program in a breast diagnostic clinic

\author{
by Margaret I. Fitch, Judith McPhail, and Edmee Franssen
}

\section{Abstract}

The purpose of this study was to evaluate the short-term effectiveness of a breast self-examination (BSE) teaching program on women's knowledge about BSE, proficiency in performing BSE, and motivation to perform BSE. The program was developed for delivery by nurses in a breast diagnostic clinic, a clinic designed to meet the need for expeditious management of breast disease, current information about breast cancer risk, surveillance, and counselling. A convenience sample of 68 women attending the clinic in a regional cancer centre participated in a pre-and five month post-teaching program evaluation. The Toronto Breast Self Examination Instrument was used as the evaluation tool. There were statistically significant changes following the teaching program in the areas of knowledge about the correct technique for performing BSE, proficiency performing BSE, and confidence about finding changes when performing BSE. No significant changes were observed in motivation to practise BSE, although group scores did improve following the education. Participants found the video presentation and the review of BSE information pamphlets by the nurse to be the most helpful components of the BSE teaching program.

Breast cancer continues to be the most frequently diagnosed cancer for Canadian women (NCIC, 2000). With no prospects for primary prevention in the foreseeable future, there has been increased emphasis on early detection of the disease. Breast self-examination (BSE), as a technique for breast cancer detection, has the appeal of being self-generated, non-intrusive, inexpensive, and avoiding radiation risk. BSE is simple to do and can be performed in approximately 10 minutes (Mayer \& Solomon, 1992).

An estimated $70 \%$ of breast cancers are discovered by women themselves. However, these tumours are usually found by accident, not as part of a BSE program (Hall, 1992). BSE may enhance detection of interval cancers that occur between routine screening examinations (Baines \& To, 1990). A woman who knowledgeably performs BSE can facilitate diagnosis by drawing her physician's attention to newly developed abnormalities. In addition, she will avoid the false reassurance that may follow negative results from mammography or clinical breast examination (Harvey, Miller, Baines, \& Corey, 1998).

Despite uncertainty regarding the effectiveness of BSE in influencing outcomes, particularly mortality reduction (Baines, 1997; Gastrin et al., 1994; Harvey, Miller, Baines, \& Corey, 1997; Newcomb et al., 1991; Thomas et al., 1997), education about BSE is offered as part of a total breast health package, which also includes mammography and clinical breast examination, in our breast diagnostic clinic. The educational program was developed for delivery by nurses in an ambulatory practice and includes multiple teaching strategies. This article describes the evaluation of this BSE educational intervention.

Before one can determine the effectiveness of BSE for early detection in breast cancer, it is imperative to determine that BSE teaching programs are effective in producing expected performance and compliance (Alcoe, Gilbey, McDermot, \& Wallace, 1994). Additionally, educational interventions need to be evaluated within the context or environment in which they are delivered (Brooten \& Naylor, 1995; Hailey, Lalor, Byrne, \& Starling, 1992). Factors in the situation may have an influence on the effectiveness of an educational program. Our interest was to evaluate the effectiveness of our BSE teaching program as it was delivered in a busy ambulatory setting.

\section{Background}

The Canadian National Breast Screening Study (NBSS) suggests that most women who enter screening programs upgrade their BSE skills if subjected to brief periods of repeated instruction (Baines \& To, 1990). Two extensive reviews of relevant literature on BSE education concluded that training can improve compliance, confidence, and proficiency (Clarke \& Savage, 1999; Nettles-Carlson \& Smith, 1988).

\section{ABRÉGÉ: \\ ÉVALUATION D'UN PROGRAMME D'AUTO-EXAMEN DES SEINS DANS UNE CLINIQUE DIAGNOSTIQUE DU SEIN}

Cette étude avait pour but d'évaluer l'efficacité à court terme d'un programme d'enseignement de l'auto-examen des seins (AES) relativement aux connaissances des femmes concernant l'AES, leur compétence d'utilisation de cet examen et leur motivation à l'employer. Le programme a été conçu pour être dispensé par les infirmières d'une clinique diagnostique du sein ayant pour mandat de répondre aux besoins relatifs à la gestion diligente du cancer du sein, à la diffusion d'information à jour sur les risques, à la surveillance et aux consultations. L'échantillon de convenance comprenait 68 femmes qui participaient au programme offert par la clinique située dans un centre régional de cancérologie; l'évaluation du programme d'enseignement se divisait en deux volets: le premier préalable à la tenue du programme et le second cinq mois après sa fin. L'instrument d'évaluation retenu était l'Instrument d'auto-examen des seins de Toronto. Des changements statistiquement significatifs marquaient la tenue du programme d'enseignement dans les domaines suivants: connaissances relatives à la technique appropriée d'exécution de l'AES, compétence d'utilisation de l'AES et degré de confiance dans le repérage de changements lors de l'exécution de l'AES. On n'a remarqué aucun changement significatif au niveau de la motivation à exécuter l'AES, bien que les résultats du groupe se soient améliorés à la suite de la dispensation de l'enseignement. Selon les participantes, la présentation vidéo et l'analyse de la documentation sur l'AES effectuée par l'infirmière constituaient les composantes les plus utiles de ce programme d'enseignement de l'AES.

Margaret I. Fitch, RN, PhD, is head of oncology nursing and supportive care at Toronto-Sunnybrook Regional Cancer Centre and one of the co-directors of the Toronto-Sunnybrook Psycho-Social Behavioural Research Group, Toronto, Ontario.

Judith McPhail, RN, MHSc, is a primary nurse at Toronto-Sunnybrook Regional Cancer Centre.

Edmee Franssen, MSc, is a biostatistician at Toronto-Sunnybrook Regional Cancer Centre. 
Although teaching BSE does improve practice, it is not yet clear which aspects of teaching protocols contribute the most to proficient practice, or whether group or individual approaches are more effective (Clarke \& Savage, 1999). In general, the use of multiple strategies has emerged (Agars \& McMurray, 1993). For example, the addition of a formal instructional class to physician encouragement increased accuracy in BSE assessment (Strickland et al., 1997), and Champion (1989) found that women whose knowledge and technique were reinforced by a nurse or physician practised BSE more regularly. In 1995, Champion reported that a teaching protocol consisting of information, BSE demonstration, and return demonstration significantly increased logged proficiency, observed proficiency, and nodule detection one year post intervention. In another study (Katic, Lang, \& Budak, 1996), a method which included theory, group discussion, practical training on a silicon breast model, individual practice of BSE, and additional individual assessment of acquired skill was effective in increasing the number of women practising BSE. The use of an interactive multimedia strategy resulted in greater learning about breast health for younger women in a general practice setting (Street, van Order, Bramson, \& Manning, 1998).

Development of an education program must take into consideration the target population, potential barriers to performance of the desired behaviour, proven teaching modalities for the topic, and the environment or setting. The target population for the breast diagnostic clinic is women under the age of 50 who are perceived to be at increased risk for breast cancer. Although the issue of breast cancer in younger women has received more attention in recent years, little is known about the surveillance patterns and psychological characteristics of younger women who are at increased risk for the disease (Lerman, Kash, \& Stefanek, 1994). This age group is important for BSE teaching because of the large number of Canadian women born between 1946 and 1966 (baby boomers) and the fact that breast screening guidelines for mammography in this country target women over the age of 50 .

Certain characteristics have been identified in persons who do practise BSE. These characteristics include receiving personal instruction in BSE technique, as well as individual recommendations to perform BSE; having a sense of confidence in performing BSE; holding a belief in the personal value of performing the procedure; and perceiving a lack of barriers in carrying out BSE (Leight \& Leslie, 1998). Variables that have shown a consistent relationship with increased BSE include knowledge of BSE technique, belief in BSE as a detection procedure, and self-confidence in performing BSE (Hailey, et al., 1992). Conversely, potential barriers to regular performance of BSE include a lack of confidence in the ability to perform BSE, extensive reliance on physicians for screening, difficulty remembering to perform the behaviour, and anxiety about breast cancer and BSE (Nettles-Carlson \& Smith, 1988). Although the literature presents conflicting perspectives, it is believed that anxiety, especially in younger women or those with higher levels of education, is thought to motivate attendance at a breast cancer screening facility (Gram \& Slenker, 1992). The content of one's BSE teaching program needs to consider these various issues.

The breast diagnostic clinic (BDC) of the Toronto-Sunnybrook Regional Cancer Centre (T-SRCC) was established to meet the need for expert, expeditious management of breast disease including the provision of current information on breast cancer risk, counselling, and surveillance. The BDC is held one evening each week in the regional cancer centre. The clinic attracts a population of women under the age of 50 who are or perceive themselves to be at increased risk of breast cancer and who refer themselves to the clinic. An interdisciplinary team including family physicians, surgeons, nurses, and a psychologist provides care. Patient education is a priority. The nurse-physician interaction is collaborative, with physicians frequently setting the stage for BSE training and the nurse providing the indepth instruction.

Given the pace of the breast diagnostic clinic, the relatively short appointment times, the environment of a cancer setting, the age of the women attending the clinic, and the perceived anxiety of those in attendance, the BSE teaching program was designed to be delivered by the nurse within the context of the clinic appointment. The educational challenge was to provide the necessary information and opportunity for skill development in a short time period when the learner may be worried about a cancer diagnosis. The BSE program was designed to influence knowledge about breast cancer risk and BSE as a method of detection, as well as improving skill and confidence in performing BSE.

The BSE teaching program consisted of four components: 1) BSE information pamphlets which the nurse reviewed with the patient, 2) a video that addressed the benefits of BSE and clearly demonstrated the proper technique, 3) demonstration of BSE by the nurse using the patient as the model, and 4) return demonstration by the patient on herself with the nurse observing. A breast model was used for the second demonstration if the patient expressed difficulty in feeling lumps. The teaching took about 20 minutes to complete.

\section{Purpose}

The purpose of this study was to evaluate the short-term effectiveness of an educational intervention on desired learning outcomes: a) knowledge about BSE, b) proficiency in performing $\mathrm{BSE}$, and c) motivation to practise BSE. The BSE teaching program incorporated a combination of teaching strategies shown to be effective in other settings. However, it was important to determine if the program being delivered was effective in the context of the breast diagnostic clinic.

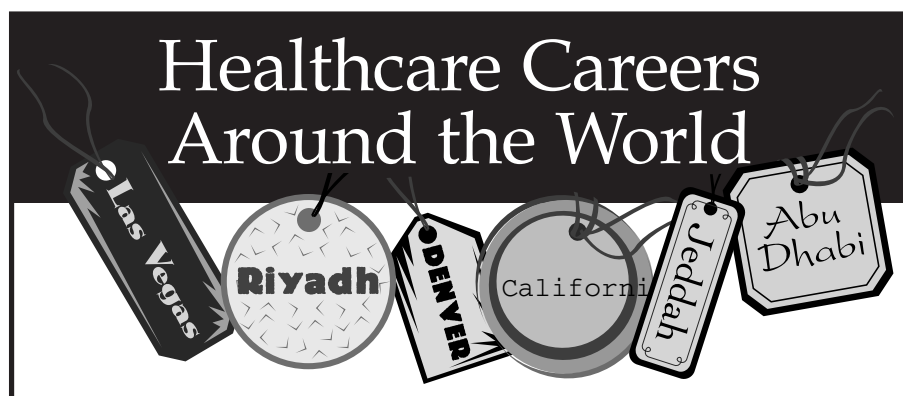

Positions are available, in the United States, for registered nurses with a minimum of 1 year experience.

Registered nurses with a minimum of 2 years experience are also needed in Jeddah, Riyadh, Abu Dhabi and Dubai.

- Head Nurse - Adult/Pediatrics

- Nurse Clinician - Adult/Pediatrics

- Oncology/Hematology - Adult/Pediatrics

- BMT - Adult/Pediatrics

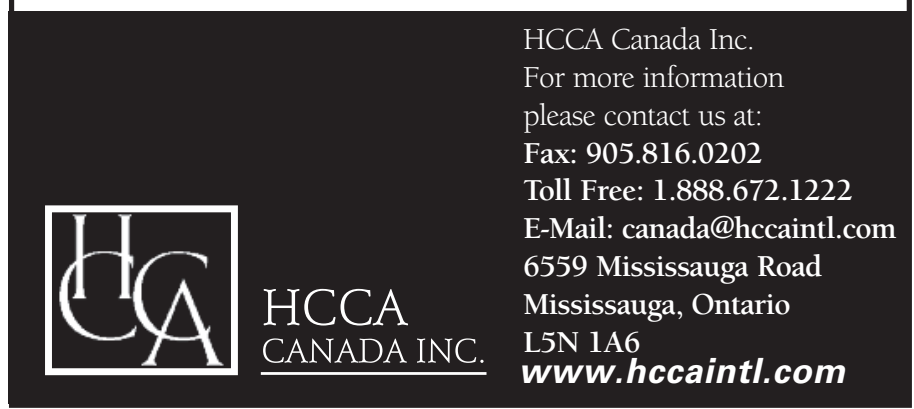




\section{Methods}

\section{Procedures}

The evaluation used a pre-post test approach. All new patients registered for assessment in the breast diagnostic clinic (BDC) during a six-month interval were approached regarding participation in the study. The only ineligibility criteria were the inability to speak or read English and having received BSE instruction within the previous month. Those who were eligible but declined participation in the evaluation still received the educational program. Those who agreed to participate in the evaluation completed two instruments, the Toronto Breast Self-Examination Instrument (TBSEI) (Ferris, Shamian, \& Tudiver, 1991) and the State-Trait Anxiety Inventory (STAI) (Spielberger, Gorsuch, Lushene, Vagg, \& Jacobs, 1983), prior to undergoing the BSE teaching program. Immediately following completion of the program, participants completed the TBSEI knowledge subscale. Five months later, women completed the entire TBSEI again and rated which part of the BSE teaching program they had found most helpful. Ethical approval for this evaluation study was given by the Sunnybrook Health Science Centre Research Ethics Committee.

\section{Sample}

Of the 145 new patients registered for assessment in the BDC during the six-month evaluation period, 68 were ineligible or declined to participate in the evaluation study. Women were ineligible for the following reasons: not being able to speak English $(n=8)$; recently taught BSE $(n=9)$; and other $(n=6)$, such as pregnancy and cognitive impairment. The reasons women gave for not wanting to participate included not enough time to stay at the clinics and participate $(n=31)$, scheduled for tests or surgery $(n=9)$, and feeling too upset $(n=5)$.

Seventy-seven women gave written, informed consent to participate in the study. However, nine of them (12\%) did not complete the TBSEI at the five-month interval, so the final sample size was 68. These nine women represented a cross-section of breast cancer risk categories, anxiety scores, and reported frequency of BSE. Evaluation tools

Basic demographic information, including age, marital status, education level, source of referral, and risk status for breast cancer, was obtained from the patient's chart. The outcomes of interest, including knowledge about BSE, proficiency in performing BSE, and motivation to perform BSE, were assessed using the TBSEI (Ferris et al., 1991). This instrument provides a standardized selfadministered measurement with established reliability estimates and validity properties (Ferris et al.). The TBSEI's three scales include proficiency (frequency and proficiency of BSE practice), knowledge (knowledge of breast cancer and of BSE), and motivation (perceived susceptibility and reasons for BSE practice). The 60 items are precoded and the tool usually requires 15 minutes to complete. Although it is theoretically ideal to assess proficiency of practice through observation, the paper-and-pencil approach was used in this evaluation to reduce the need for office visits and highly trained personnel. Additionally, the TBSEI allows for the assessment of various steps concerning appropriate BSE practice (i.e., correct technique, appropriate frequency).

Subscale scores for knowledge about BSE are calculated using a five-point scale with each of the 20 items and the following options: strongly disagree (scored as a -2 ), disagree $(-1)$, neither agree nor disagree $(0)$, agree $(+1)$, and strongly agree $(+2)$. The range in potential scores for this subscale is -40 to +40 .

Scores for proficiency included answers to items about frequency of BSE, proficiency of practice and self-confidence. Scores are calculated using five-point options with the exception of one question that has a seven-point option. The TBSEI scoring system was originally designed to identify habitual performers. It was adapted in this study to reflect the ideal situation (i.e., BSE performed 10 to 12 times per year). Thus high proficiency scores reflect monthly and systematic BSE practice. The range in potential proficiency scores is 0 to 11 .

Subscale scores for motivation are calculated using a five-point scale with each of the items and the following options: strongly disagree, disagree, neither disagree nor agree, agree, strongly agree. A "neither agree nor disagree" was scored a " 0 " in accordance with the scoring guidelines of the TBSEI (Ferris et al., 1991). The range of potential scores for this subscale is -32 to +32 .

The STAI (Spielberger et al., 1983) has established reliability and validity properties and measures anxiety both as a situational response and as a personality trait. The instrument has 40 items with precoded answers and takes about 10 minutes to complete. Scores are generated for both state and trait anxiety. Within this study, anxiety was measured as a baseline variable because of its possible influence on BSE and breast screening behaviours.

Participants' perspectives on the helpfulness of the various components of the BSE teaching program were gathered at five months. A list of the components of the BSE program was provided and the women were asked to indicate which ones were most helpful to them.

\section{Analysis}

Data were entered into an ORACLE database and analyzed using SAS UNIX (statistical software package SAS Institute Inc). Item frequency counts and total scores were calculated for the TBSEI and STAI at baseline (time one) and the TBSEI at five months (time three). Frequency counts and total scores were calculated for the knowledge subscale of the TBSEI for time two (immediately after completion of the BSE teaching program). Frequency counts were also calculated for demographic items. Given there are no absolute values for high and low anxiety published for the STAI, we used the median as the cut-off point. For both baseline trait and state anxiety scores, participants were divided into two groups, those with anxiety scores above the median and those with scores below the median. Baseline knowledge, proficiency, and motivation scores were compared for these two groups using t-tests. Participants were also grouped on the basis of their risk for breast cancer (i.e., those at or slightly above general population risk for breast cancer and those with moderate/high risk for breast cancer). Baseline anxiety scores for these risk groups were compared using t-tests.

\section{Table One: Selected sample demographics} $(n=68)$

\begin{tabular}{|l|c|}
\hline Characteristic & Frequency \\
\hline Age in years & \\
$20-29$ & 14 \\
$30-39$ & 24 \\
$40-49$ & 24 \\
$50-59$ & 4 \\
$60-69$ & 2 \\
\hline Marital status & \\
Single & 11 \\
Married/common law & 53 \\
Divorced/other & 4 \\
\hline Highest education completed & 1 \\
Primary school & 10 \\
High school & 12 \\
Some college/Some university & 16 \\
College & 29 \\
University & \\
\hline
\end{tabular}


Taking into consideration independence of the subjects and distribution of the variables, appropriate statistical tests (analysis of variance, t-tests, McNemar) were used to determine differences in knowledge, proficiency and motivation following the teaching program. Differences in knowledge were compared for two intervals: 1) pre-teaching vs immediately after teaching, and 2) pre-teaching vs five months following teaching. Differences in motivation and proficiency were compared for pre-teaching and five months postteaching. To adjust for multiple testing, $\mathrm{p}$ values were considered significant at 0.001 .

\section{Results}

\section{Sample characteristics}

Sixty-eight women completed the evaluation measures at all data collection points. The demographic characteristics for this sample are presented in Table One. The women ranged in age from 20 to 69 years of age, with those in the middle years (30 to 49 years) comprising $35 \%$ of the sample. Eighty-seven per cent of the women were Caucasian and $75 \%$ were married. Eighty-four per cent completed some post-secondary school and $43 \%$ completed university. Although their occupations varied, most women worked in business $(24 \%)$ or health care $(19 \%)$, or were homemakers $(22 \%)$.

The majority $(78 \%)$ of the women were referred to the breast diagnostic clinic by physicians. Many had had previous exposure to BSE through brochures (59\%), physicians (49\%), breast cancer education program $(11 \%)$, relatives $(10 \%)$, nurses $(7 \%)$, and television (6\%). Only $4 \%$ had not had previous exposure to BSE instruction at some point in time.

Forty-seven per cent were categorized as "at moderate/high risk" for breast cancer and 53\% as "at or slightly above general population risk." None of the women had ever been treated for breast cancer, although $29 \%$ had received treatment for benign breast disease. A majority $(78 \%)$ of the women were still having menstrual periods. Eighty-one per cent of the women had been pregnant and their mean age at first live birth was 27 years.

\section{Anxiety}

At baseline, the mean trait anxiety score was 40.2 (standard deviation 8.6), with a range of 28 to 62 . The mean state anxiety score was 38.2 (standard deviation 10.4), with a range of 21 to 64. The median anxiety score for the participants was 37.5 .
The student t-test revealed no significant differences in anxiety scores $(n=68$, trait, $p=0.2515$; state, $p=0.3104)$ between the group of women with "at or slightly above general population risk for breast cancer" and those in the group of "moderate/high risk for breast cancer." There were also no significant differences concerning anxiety scores in relation to education level (trait, $\mathrm{p}=$ 0.446 ; state $\mathrm{p}=0.464$ ) or age (trait, $\mathrm{p}=0.212$; state, $\mathrm{p}=0.947$ ). No significant differences were observed for knowledge, proficiency, or motivation at baseline in relation to anxiety (see Table Two).

\section{Knowledge}

Participants' knowledge scores at baseline (before BSE teaching program) ranged from three to 39 with an average score of 18.5 (standard deviation $=0.4$ ). Immediately after the BSE teaching program, participants' knowledge scores ranged from four to 36 with an average of 24.1 (standard deviation $=8.6$ ). Five months after the BSE teaching program, participants' knowledge scores ranged from 2 to 40 with an average of 22.5 (standard deviation $=8.3$ ).

Based on results from repeated measures of analysis of variance, there was a statistically significant time effect $(p<0.0001)$ on the participants' knowledge scores between the three different measurement points. The mean change of score in participants' correct responses to the knowledge items was $5.5(\mathrm{p}<0.004)$ from the time before teaching to immediately after the BSE program, whereas the mean change was $4.1(\mathrm{p}<0.0001)$ from the time before the teaching to five months after the BSE program. Seventy-eight percent of the women had a higher score immediately after the BSE teaching program than at baseline and $87 \%$ of these maintained a higher score five months after the BSE teaching.

Of particular clinical importance, at baseline none of the participants provided correct answers for the five questions regarding the steps of the BSE procedure. At five months, 13 women (19.1\%) provided correct answers to all five questions. The difference in the proportion of women who provided the correct answer was statistically significant (McNemar's test statistic $=13, \mathrm{p}<0.0001)$.

Selected knowledge questions reflected modest change following the teaching program. At baseline, $96 \%$ of the participants reported learning the BSE technique previously. However, only $68 \%$ of the women responded correctly to the item regarding the best time of the month to perform BSE before a women reaches menopause. At five months, $93 \%$ of the women responded correctly to this item (McNemar's test statistic=7.12, p<0.01). In response to the item, "the best time to perform BSE after a

Table Two: Exploring the influence of anxiety on proficiency, motivation, and knowledge scores at baseline $(n=68)$

\begin{tabular}{|l|c|c|c|}
\hline & $\begin{array}{c}\text { Proficiency scores } \\
\text { (mean/sd) }\end{array}$ & $\begin{array}{c}\text { Motivation scores } \\
\text { (mean/sd) }\end{array}$ & $\begin{array}{c}\text { Knowledge scores } \\
\text { (mean/sd) }\end{array}$ \\
\hline $\begin{array}{l}\text { Groups based on } \\
\text { trait anxiety scores }\end{array}$ & $2.6(2.2)$ & $14.6(4.8)$ & $20.7(7.6)$ \\
Below 39 (n=36) & $2.3(2.0)$ & $12.1(6.1)$ & $16.1(8.7)$ \\
39 and above (n=32) & $2.6(2.1)$ & $14.2(4.9)$ & $19.6(7.1)$ \\
\hline $\begin{array}{l}\text { Groups based on } \\
\text { state anxiety scores }\end{array}$ & $12.6(6.2)$ & $17.5(9.5)$ \\
Below 37.5 (n=34) & $2.3(2.1)$ & & \\
37.5 and above (n=34) & & $12.1)$ & \\
\hline
\end{tabular}

No significant differences observed between means woman reaches menopause is at the same time each month," $60 \%$ agreed with this statement at baseline and $93 \%$ agreed with it five months later (McNemar's test statistic, $\mathrm{p}<0.0001)$. Knowledge about the incidence of breast cancer did not improve. Ten per cent of the participants at baseline agreed that the incidence of breast cancer increases with age, while $7 \%$ agreed with the statement at five months.

\section{Proficiency}

At baseline, participants' proficiency scores ranged from 0 to 8 , with an average of 2.5 ( standard deviation $=2.1)$. Five months following the intervention, proficiency scores ranged from 0 to 11 , with an 
average of 5.9 (standard deviation $=3.1$ ) The mean score for changes in proficiency scores was 3.4 ( A significant increase in the mean proficiency scores was observed from baseline to five months following the BSE teaching program using a paired t-test $(\mathrm{p}<0.0001)$.

Of clinical interest, participants were asked how often they performed BSE during the past 12 months. At baseline, 12\% reported a frequency of performance that was the ideal ("10-12 times") and five months later, $18 \%$ reported a performance of " 10 12 times." At baseline, $43 \%$ reported a performance that was poor ("not at all" or "one-three times") and five months later, only $26 \%$ reported a performance that was poor. Although a general trend toward increased frequency of performance was observed five months following the BSE teaching program, the difference was not statistically significant.

Confidence levels in performing BSE increased following the BSE teaching program. At baseline, $12 \%$ of the participants reported feeling "very confident" or "confident" they could find changes when they performed BSE. At five months, $40 \%$ of the participants reported feeling "very confident" or "confident." The difference in the proportion of women feeling confident is significant (McNemar's test statistic $=16.2$, $\mathrm{p}<0.005)$.

\section{Motivation}

Baseline motivation scores ranged from -2 to 25 , with an average of 13.43 (standard deviation $=5.6$ ). Five months after the educational intervention, scores ranged from -2 to 22 , with an average of 14.0 (standard deviation $=5.6$ ). From baseline to five months following the BSE teaching program, the mean score for changes in motivation was 0.6 (standard deviation $=5.0$ ). Using a paired t-test, no significant difference in motivation scores was observed between baseline and five months following the BSE teaching $(\mathrm{p}=0.340)$.

\section{Helpfulness of the BSE program}

Some participants provided an indication of the components of the BSE teaching program they found helpful. The components rated as most helpful included the video $(n=25)$, review of information pamphlets by the nurse $(n=17)$, demonstration by the nurse $(n=9)$, and return demonstration by the patient $(n=5)$. Participants also noted that knowledge of BSE, proficiency in performing BSE, as well as knowing what to do when changes in the breast were observed, were aspects that required continual reinforcement.

\section{Discussion}

This study was undertaken to evaluate the effectiveness of a teaching program about BSE on women's knowledge, proficiency, and motivation. The program was designed for implementation in a breast diagnostic clinic. It was delivered in the context of a clinic appointment by an oncology nurse.

The main limitations of this evaluation were the self-selected nature of the clinic population and the lack of a control group. Women seeking breast cancer screening already constitute a more motivated group than those who choose not to attend. Women who come to the diagnostic clinic, and hence those in this sample, may have a higher incidence of breast problems, a stronger family history, and be more knowledgeable of the risk involved when breast cancer is not detected early than the general population (Morrison, 1996). Another limitation lies in the self-reporting of frequency and proficiency of BSE. These may have been inflated by a self-report bias. Finally, the educational level of participants is higher than the general population, although the sample reflects the registrants at the breast diagnostic clinic.
Of the participants, $91 \%$ were under the age of 50 and $47 \%$ were categorized as moderate/high risk for breast cancer. This illustrates the enhanced awareness of breast cancer in young, well-educated women. Thirty per cent of diagnosed breast cancer cases occur before the age of 50 years (NCIC, 2000). For women under 50 who are not eligible for organized screening programs, early detection appears to require an approach encouraging regular BSE, thus emphasizing the need for effective instruction programs with information relevant to the targeted population.

Major findings concur with prior research concerning effectiveness of an educational intervention on women's knowledge, proficiency, and motivation for BSE practice. Our results indicate improvement in self-reported proficiency scores and provide additional support that the teaching of BSE will produce a significant increase in the reported frequency of practice and level of confidence over an extended period of time (Alcoe et al., 1994). The importance of confidence in performing BSE is consistent with self-efficacy theory which suggests that confidence in one's skills will predict adoption and persistence of any health behaviour (Bandura, 1977).

Participants' overall knowledge of breast cancer and BSE showed positive changes with improvement immediately after the educational intervention, and a minimal decrease five months following the intervention. However, key messages were lost, such as the breast cancer risk factor of age. This observation raises questions about the learning environment and whether younger women at increased risk for breast cancer may be selective about what knowledge is needed or retained. As well, health information may seem filled with inconsistencies and make it difficult for individuals to decide what has relevance for them. Alonzo (1993) suggests that health educators may well face a significantly desensitized population. Clear information is needed to increase breast cancer knowledge.

The emphasis of the education program was on BSE proficiency. The increase in the proportion of women who answered five questions about the BSE procedure correctly on the proficiency scale was significant. A significant positive relationship between knowledge and observed BSE quality has been reported elsewhere (Alagna and Reddy, 1984).

Participants' motivation scores improved only slightly after intervention. This may be influenced by the nature of the sample. Only $18 \%$ of our participants reported BSE practice of 10-12 times a year at five months. Other authors have reported rates of $46 \%$ in a sample of registered nurses (Budden, 1998) and 82\% in a sample of women in a general practice setting (Katic et al., 1996). Although it is difficult to compare these populations, the variations in performance along with the links to motivation and beliefs about BSE are worthy of future investigation.

For the participants in this evaluation, there was no difference in anxiety between the categories of risk for breast cancer. This finding differs from results of a study with younger women (under age 50) at increased risk for breast cancer who reported serious psychological morbidity (Lerman et al., 1994). Perhaps women's cancer anxiety levels were ameliorated by mere attendance at a surveillance clinic where their concerns around risk can be addressed.

Based on our findings, we plan to maintain the BSE educational intervention in our breast diagnostic clinic with its emphasis on experiential learning and self-care management. Teaching BSE will continue to be an integral component of nursing practice because participants favoured the involvement by a nurse in the explanation of BSE and guided experience. The video presentation will also be utilized together with the other program components. Although participants found the BSE video presentation helpful, as also noted by DeMuth (1989), the video still requires one-on-one interaction with the physician or nurse. 


\section{Conclusion}

These evaluation results support the effectiveness of the BSE teaching program on participants' proficiency, including selfconfidence and knowledge about the BSE procedure, over a fivemonth period. However, the duration of follow-up was limited. We do not know the effectiveness of the intervention during the maintenance phase (i.e., one to two years after intervention). Key messages about breast cancer risk were not improved. The review by the nurse and the video presentation were the most favoured parts of the intervention.

Resources for this type of instruction required special training of nurses, 15 to 20 minutes of a registered nurse's time, a breast model, a VCR/video that is available in most clinics and physicians' offices, and pamphlets that were donated by the Cancer Society or pharmaceutical companies. For a small capital investment and operating costs for BSE education, there are benefits for both women's health and the health care system.

\section{Acknowledgements}

We thank Susan Bowles, RN, for her teaching assistance and Dr. P. Chart for expert assistance in reviewing earlier versions of this manuscript. The evaluation study was funded by the Canadian Breast Cancer Foundation, Ontario Chapter.

\section{References}

Agars, J., \& McMurray, A. (1993). An evaluation of comparative strategies for teaching BSE. Journal of Advanced Nursing, 18, 1595-1603.

Alagna, S.W., \& Reddy, D.M. (1984). Predictors of proficient technique and successful lesion detection in BSE. Health Psychology, 3, 113-127.

Alcoe, S.Y., Gilbey, V.J., McDermot, S.R., \& Wallace, D.G. (1994). The effects of teaching breast self-examination: Reported confidence and frequency of practice over a sixyear period. Patient Education and Counselling, 23, 1321.

Alonzo, A.A. (1993). Health behaviour: Issues, contradictions and dilemmas. Social Science Medicine, 37(8), 1019-34.

Baines, C.J. (1997). Reflections on BSE. [Editorial]. Journal of the National Cancer Institute, 89(5), 339-40.

Baines, C.J., \& To, T. (1990). Changes in BSE behaviour achieved by 89,835 participants in the Canadian National Breast Screening Study. Cancer, 66, 570-576.

Bandura, A. (1977). Self-efficacy: Toward a unifying theory of behavioral change. Psychology Review, 84(2), 191-215.

Brooten, D., \& Naylor, M.D. (1995). Nurses' effect on changing patient outcomes. Image, 27(2), 95-99.

Budden, L. (1998). Registered nurses' breast self examination practice and teaching to female clients. Journal of Community Health Nursing, 15(2), 101-12.

Champion, V.L. (1989). Effect of knowledge, teaching method, confidence and social influence on BSE behaviour. Image, 21, 7680.

Champion, V.L. (1995). Results of a nurse-delivered intervention on proficiency and nodule detection with breast self-examination. Oncology Nursing Forum, 22(5), 819-824.

Clarke, V.A., \& Savage, S.A. (1999). Breast self-examination training: A brief review. Cancer Nursing, 22(4), 320-6.

DeMuth, J.S. (1989). Patient teaching in the ambulatory setting. Nursing Clinics of North America, 24(3), 645-654.

Ferris, L.E., Shamian, J., \& Tudiver, F. (1991). The Toronto Breast Self-Examination Instrument (TBSEI): Its development and reliability and validity data. Journal of Clinical Epidemiology, 44(12), 1309-1317.

Gastrin, G., Miller, B.M., To, T., Aronson, K.J., Wall, C., Hakama, M., Louhivuori, K., \& Pukkala, E. (1994). Incidence and mortality from breast cancer in the Mama program for breast screening in Finland, 1973-1986. Cancer, 73(8), 2168-2174.

Gram, I.T., \& Slenker, S.E. (1992). Cancer anxiety and attitudes toward mammography among screening attenders, nonattenders, and women never invited. American Journal of Public Health, 82(2), 249-251.

Hailey, B.J., Lalor, K.M., Byrne, H.A., \& Starling, L.M. (1992). The effects of self-reinforcement and peer-reinforcement on the practice of breast self-examination. Health Education Research: Theory \& Practice 7(2), 165-174.
Hall, L.S. (1992). BSE: Use of a visual reminder to increase practice. American Association of Occupational Health Nurses Journal, 40(4), 186-192.

Harvey, B.J., Miller, A.B., Baines, C.J., \& Corey, P.N. (1997). Effect of breast self-examination techniques on the risk of death from breast cancer. Canadian Medical Association Journal, 157(9), 1205-1212.

Harvey, B.J., Miller, A.B., Baines, C.J., \& Corey, P.N. (1998). Authors response to letter to editor. Journal of the Canadian Medical Association, 158(4), 472.

Katic, M., Lang, S., \& Budak, A. (1996). Evaluation of the general practice program of women education for breast self-examination. Acta Medical Croatica, 50(4-5), 185-91.

Leight, S.B., \& Leslie, N.S. (1998). Development of a competencybased curriculum for training women in breast self-examination skills. Journal of American Academy of Nurse Practitioners 10(7), 297-302.

Lerman, C., Kash, K., \& Stefanek, M. (1994). Younger women at increased risk for breast cancer: Perceived risk, psychological well-being, and surveillance behaviour. Journal of the National Cancer Institute Monographs, 16, 171-176.

Mayer, J.A., \& Solomon, L.J. (1992). BSE skill and frequency: A review. Annals of Behavioral Medicine, 19(3), 189-196.

Morrison, C. (1996). Determining crucial correlates of BSE in older women with low incomes. Oncology Nursing Forum, 23(1), 83-93.

National Cancer Institute of Canada. [NCIC]. (2000). Canadian cancer statistics 2000. Toronto, ON: Author.

Nettles-Carlson, B., \& Smith, L. (1988). Self-examination in the early detection of breast cancer: Issues and implications for nursing practice and research. Health Care for Women International, 9, 337-352.

Newcomb, P.A., Weiss, N.S., Storer, B.E., Schools, K.D., Young, B.E., \& Voigt, L.F. (1991). Breast self-examination in relation to the occurrence of advanced breast cancer. Journal of National Cancer Institute, 83, 260-5.

Spielberger, C.D., Gorsuch, R.L., Lushene, R., Vagg, P.R., \& Jacobs, G.A. (1983). State-trait anxiety inventory (Form Y). Mind Garden, Palo Alto, CA: Consulting Psychologists Press, Inc.

Street, R.L. Jr., van Order, A., Bramson, R., \& Manning, T. (1998). Preconsultation education promoting breast cancer screening: Does the choice of media make a difference? Journal of Cancer Education, 13(3), 152-61.

Strickland, C.J., Feigl, P., Upchurch, C., King, D.K., Pierce, H.I., Grevstad, P.K., Bearden, J.D. III, Dawson, M., Loewen, W.C., \& Meyskens, F.L. Jr. (1997). Improving breast self-examination compliance: A Southwest Oncology Group randomized trial of three interventions. Preventive Medicine, 26(3), 320-332.

Thomas, D.B., LiGao, D., Self, S.D., Allison, C.J., Tao, T., Mahloch, J., Ray, R., Qin, Q., Presley, R., \& Porter, P. (1997). Randomized trial of BSE in Shanghai: Methodology and preliminary results. Journal of the National Cancer Institute, 89(5), 355-364. 